\title{
The Discussion about the Common Psychological Barriers and Its Transformation of Female Students in Colleges in the PE Teaching
}

\author{
Liu $\mathrm{Li}^{1}$ \\ ${ }^{1}$ Department of Physical Education, Qingdao University of Science and Technology, Qingdao, China \\ Correspondence: Liu Li, Department of Physical Education, Qingdao University of Science and Technology, \\ Qingdao, China. E-mail: 13969851549@163.com
}

Received: July 1, 2013 Accepted: July 3, 2013 Online Published: August 30, 2013

doi:10.5539/ass.v9n11p327 URL: http://dx.doi.org/10.5539/ass.v9n11p327

\begin{abstract}
Physical education (PE) in colleges is a part of college education system, the quality of the PE class of the female students will directly affect their corporeity, the whole school's physical education and even the quality of the cultivation of talents in colleges. So we should pay more attention on the quality of college female students' PE class. Generally speaking, the age of college female students is ranking from 17 to 23 , which is close to or have reached the age of adults. Differences exist between girls and boys both physiologically and psychologically during this time. So we should firstly solve problems mentally if we want to have a PE class for female students in which they can do efficiently. We should deal with those problems in a reasonable way, motivate their enthusiasm to have a PE class, cultivate their interests towards PE and urge them to form a habit of exercise consciously according to the girls' physiological characteristics and the physiological barriers that affect their interests to the class. According to the physiological barriers the college girls showed in the PE class, the author makes the following analysis and study.
\end{abstract}

Keywords: psychological barriers, PE teaching, female students in colleges

\section{The Analysis of Female Students' Physiological Barriers in Physical Education}

The mainly physiological barriers that affect female students' attitudes toward PE class are the following aspects:

\subsection{Contempt Psychology}

Since some certain primary and middle schools value intelligence cultivation rather than physical education, and pursue enrolment rate superficially, some college students rarely go to PE classes when they are in high school. Therefore, their views about PE are superficial and a general contempt psychology that the PE class does not indispensably exists. Those students harbor the opinion that without PE class for three- year high school life they still have passed the entrance examination and gone to the college. So they always ask for leave when it is in a PE class. Though they sometimes come to the class, they are always in low spirit and are unwilling to do exercises on their own.

\subsection{The Fear Psychology of Bitterness, Tiredness, and Dirt}

Nowadays most college students are spoiled when they are at home, and they are "the focus target of protection" who live comfortable lives and never have a chance to experience hardship. As we all know, we usually have PE classes outside, and do exercises rain and sun. Thus some girls fear that their skin blacken, their clothes stained, their hair messed, and unwilling to go to the PE class. Especially in the sports event such as mat exercises, jumping and long-distance running those girls harbor fear psychology. The windy and dusty weather or some other bad weather make these female students more timid and then try to escape the PE class.

\subsection{Shyness}

Nowadays female college students mostly are between 17 to 23 years old. Shyness always make them worry about whether their behavior is good-looking, and whether it would provoke mockery especially when someone is looking or the place they have class is near the boy's. And this directly affected the quality of the class.

\subsection{The Love of Beauty}

Young girls love beauty, and there is no exception to female college students. This kind of psychology shown in the PE class is that they have keen interest in rhythmic gymnastics and calisthenics, while paid little attention to 
those sports event in track and field and ball sports, such as shot putting, long-distance running, long-jumping and basketball and so on. They all hope to have a slender figure and fear to get fat, some even reduce weight in a blind way. This kind of psychology hampered the all-round development of their physical fitness.

\subsection{Inferiority}

When taking part in the physical activities, some students are inactive or slow while learning actions for their bad physical fitness and the lack of perceptional ability and some are not well equipped with the study discipline and practice methods of an efficient PE class. So when they saw the other students doing well while they still doing bad after several times of practice, they then thought that they are born stupid, and lost confidence to practice again. There are still some students who are short and over-weighted and there is a long way to go to reach the physical quality required and this also leads to inferiority that affects the enthusiasm to have a PE class.

\subsection{Boredom}

We have PE classes from primary school to college. Most of the content in the teaching materials are similar and are repeated again and again. Thus some girls think that this class won't raise our sports level and it is always old-fashioned. It is so boring and dull to have the same class for we have studied it for dozens of years. Students may become bored with the PE class. They are in low spirit during the class, and do exercises passively just to meet the teacher's requirement, and always be lazy with the sport while the teacher didn't notice.

\subsection{Fear}

In physical activities, especially when doing instrumental movements, trauma is easily carried out. Some students may suffer muscle malfunction and nervous system slow response because of nervousness. Their distorted and abnormal actions are bounded to generate timidity, fear and the lack of confidence. If there were something bad happening during the last class, the student who experienced that would have this kind feeling of "once bitten twice shy". When he do that action again he would fear and tremble, and then lead to the reverse psychology towards instrumental events' practice.

\subsection{Conformity}

Following the crowd is the main feature of conformity. If there are several students in today's class are full of enthusiasm, others will be affected by this kind of atmosphere and go to the class spiritually. It is no doubt that this class is an efficient one. This is the way in which the conformity is functioned, and it is good to raising the teaching quality. But the girls' conformity to the class always is negative. For example, when she found someone else did not practice heartedly, she herself did not want to work hard. When saw someone were delighted run the long-distance running by cut across the track and followed them for fear of stand loss. These girls think the law won't punish the vast majority, and if they are punished, everyone is in the same situation. This kind of psychology generally exists among girls who are weaker in sport ability. More attentions should be paid on it.

\section{The Causes of Female Students' Psychological Barriers}

\subsection{The Character of Sports Class and the Stress of Evaluation Criterion}

At present, most of the female students in colleges are poor in the basic body quality. Sports class is different from other disciplines, the female students are always under a certain load exercise in the process of learning motor. In the usual teaching, if the exercise intensity is too small, extremely incommensurate reaction will occur in visceral organs and adverse emotional experience will emerged due to lack of the necessary energy reserves, if the exercise intensity is too large, the female students will have a feel of tiredness and fear. In addition, in colleges and universities, sports performance is a reference standard of students' employment and evaluation, this makes female students have a sense of urgency and tension. Furthermore, the female students with poor learning method will have a pessimistic mood and some basic mental disorder.

\subsection{The Movement Difficulty of the Female Students and the Fear of Danger}

Psychological barrier emerges easily if the risk in the complexity of the project is close to or more than the students' maximal endurance capacity. Minority female students with high sport talent do not feel the difficulty when they do complex coefficient sports. However, most female students' sport abilities are low, and we find that there are two different mental activities when the students do the sports from interview. One is novel and positive emotional experience. Some female students think that they can complete the sports as long as they are careful, they become self-confidence from timid and nervous. On the contrary, other female students lose confidence in themselves because of the fear of danger, thinking it is too difficult to complete the sports. When injury accident happens, their fear feeling even more aggravated. The female students will be afraid of hurt and hesitate to press forward in the fosbury flop, hurdle, horizontal bar project. 


\subsection{The Bad Health Condition of Female Students and the Bad Equipment}

Female college students are in late puberty, they are prone to fear of movement in the menstrual period due to lack of physiological health care knowledge. In addition, some girls who cannot do exercises because of chronic disease or sports injury will suffer psychological burden more easily. Sometimes, the female students will be hurt because of the backward equipment, unreasonable layout, and the improper protection of teachers, so the female students will have a negative psychology.

\subsection{The Tensions between Teachers and Students}

When we talk with the female students, we often hear such words: One student' sport is not good, but she got a high score because of her good relationship with the teacher, while I and the teacher' relationship is not good, so the teacher will not give me a high score. A kind of loneliness and depression make the individual psychology lose balance. It is easy to cause psychological barriers if the dad individual mood could not be mediated.

\section{Solving Measures}

\subsection{Pay Special Attention to the Teaching of PE Theory Classes and Solve Problems from the Ideological Aspect}

Although female college students have had PE classes for dozens of years, they still know little about the basic knowledge of physical exercises, the advantages of PE and how to go on with the physical exercises. For example, in the stand-reaching test class, when I asked the students how long is the normal-standard athletic fields, one quarter of the students could not answer my question. The starting block used in short-distance running that half of the students have never seen before. In the entrance test for freshmen, many students cannot finish the 800-meter running. Most of them may want to do some exercises after class while they do not know how to go on with it and what to do. They lack the systematic study of physical education. This is indeed a mistake in our previous PE education. It is no wander that quite a few female students take the PE class as a burden. College education is the last phase of the regular education during students` whole life. Therefore, only by teacher's systematic and oratorical explain can female students really know the function and the benefit they can get from it, and then take the PE class as a must. Their psychology thus changed from blindly to self-consciously. Their enthusiasm is also stimulated. So they become active when the class is going on and coordinate with the teacher very well. This lays a foundation of their life-long physical exercises.

\subsection{Overcome the Weakness, Solve the Problem Accordingly and Make the Teaching Progress Systematically}

It is a general phenomenon that college students are always shy and they are afraid that the strange actions they make would lead to mockery. Teachers should tell the students the meaning of proper exercises. A good PE teacher should be good at encouraging girls to practice more, and stimulate their enthusiasm by praise and encouragement, and try to avoid seeing one girl finish her actions. Teachers' wrong behavior may lead to heavy psychology burden, nervousness and fear, and then accidents followed. Teachers should help those timid ones to build up their confidence, protect them from hurt, help them in a specific way and teach them the way of self-protection. Before the practice, ask some students who do well in the study to demonstrate in order to induce the timid ones to practice and eliminate their misgivings.

Loving to be clean is a good sanitary habit which should be praised. We should have our class in a beautiful and clean environment and so is the facility. Teachers should have the pad cleaned before the sit-ups practice. So students will never worried that their clothes become dirty and they will feel the teachers' kindness and become active to practice more. The class should be interesting and attractive, and some humor stories are needed to avoid dull tedious teaching when the students are in low spirits. Girls all want to have a beautiful and slender figure, their pursuing towards beauty is especially strong. They like gymnastic rhythmic, dancing and calisthenics and behave more actively in those exercises. Then inferiority disappears and self-confidence is built up. We teachers should cultivate the talented one, let them to help weaker students and make the conformity psychology take action. Sometimes the weather is not good, some certain endurance-test is going on. Before that a spiritual encouragement is needed, and this will enhance their courage to overcome difficulties, and eliminate their fear of bitterness and tiredness.

\subsection{Enhance PE Teachers' Cultural Attainment}

Teachers are the main power to raise the teaching quality. Teachers' cultural attainment, working attitude, language art, organizing ability and morality affect students' behavior without their awareness. To eliminate their psychology barriers, teachers must have abundant psychology knowledge in which teachers could communicate with students and be close with them. Only by knowing their psychology can teachers find a good way to let the class be interesting. Teachers then know what the students think and what kind of sports they like and what kind of teaching method they prefer. So teachers and students are no longer separated now, they are friends, and they 
are willing to tell each other what they are thinking,which makes the psychological education towards each students more easilier. As PE teachers, we must never stop to learn more things, widen our knowledge, and continuously reform our teaching method and teaching style, only by doing this can we raise our teaching quality of PE .

College PE teaching is a scientific and complex work. The key point to raise the PE teaching quality to female students is to eliminate their psychological barrier. If we pay more attention to the observation, analyze the students' psychology conditions, stimulate their interests to study, and that let them realize the PE class is a must and eliminate several bad psychology I have mentioned above, then our PE education to female students will soon reach a new phase.

\subsection{Use Scientific Teaching Methods and Timely Encouragement to Arouse Female Students' Interest}

In order to stimulate most female students' interests, the school should set up physical education for girls, choose targeted teaching content and choose some little antagonism, strong flexibility and rich aesthetic project teaching, such as aerobics exercise, posture, coordination exercises. It can not only cultivate female students' good body posture rhythm and sense of beauty, but also inspire their interesting in learning. Teachers' correct and graceful demonstration, humorous languages can open female students' hearts, and enhance their study initiative.

In the sports teaching, some actions with certain dangerous will have negative effects on female students, the girls will feel fear and anxious, but their psychological barriers will disappear as long as we give timely encouragement and guide correctly. Therefore, when the female students are in trouble, the PE teachers should timely give guidance and encouragement. The teachers should also give praise and affirmation for tiny progress of the female students. In this way, the teachers not only can help female students improve their self-confidence, but also make them to become more eager to pursue knowledge and skills. At the same time, the teachers can reduce the sports difficulty properly and give female students protection and help in the sports teaching. This is conducive to improve the quality of female students' action and increase their confidence.

\subsection{Create a Good Interpersonal Environment and Help Female Students Set up a Health Communication Mentality and Self-Awareness}

People always understand their strengths and weaknesses according to others' evaluation and the contrast with others. In the sports teaching, the completion of various movements is more intuitive and visible, some female students can't to complete the action perfectly due to their high expectations or the lack of some certain aspects, so they will feel the lonely and inferior. Sports classes provide more opportunities for interaction than other disciplines, PE teachers should create a bright and pleasant interpersonal environment for students based on the characteristics of sports classes. PE teachers should be good at using the sports to help the female students who have a sense of inferiority, they can also arrange exercise activities which need to be completed through collective efforts. In this way, the teachers can make every students feel the collective success and everyone's efforts can't be separated. And the female students with psychological barriers will understand their own strengths, build confidence, and be good at getting along with other people.

In summary, the cause of female students' psychological barriers is very complex. Therefore, the teachers must strengthen their psychological guidance, encourage and help the female students to adjust their mental both inside and outside the classroom. The teachers also should develop some special sports projects according to the female students' physiological and psychological characteristics. Besides, the teachers should strengthen the ideological education of students, help them to establish correct goal and improve the confidence to overcome difficulties.

\section{References}

Cheng, Y. X. (2003). Sports psychology of new. Lanzhou: Gansu Education Publishing Feng ten.

He, M. X. (1998). Physical Education Science Research Methods. Dalian Liaoning Normal College Press.

Ji, L., \& Ming, Q. (1995). Contemporary sport psychology. Chongqing: Southwestern Normal University press.

Liu, Q. L. (2000). Physical Education. Beijing: Higher Education Press.

Ma, Q. W. (1992, February). Sports psychology. Beijing: Higher Education Press.

Shao, R. Z. (n. d.). Psychological Education. Shanghai: Shanghai Education Press.

Tao, Y. P. (2003). Protection and assistance for obstructive scared and impact analysis. Nanjing University Gymnastics College Journal, (10).

Yao, B. X. (2000). The negative tendency of school mental health and development trend. Chinese Journal of 
science education, (4).

\section{Copyrights}

Copyright for this article is retained by the author(s), with first publication rights granted to the journal.

This is an open-access article distributed under the terms and conditions of the Creative Commons Attribution license (http://creativecommons.org/licenses/by/3.0/). 